\title{
FORMAÇÃO SOCIOESPACIAL E A DUALIDADE BÁSICA DA ECONOMIA MEXICANA
}

\author{
João Vitor Sandri Coelho ${ }^{1}$ \\ José Messias Bastos²
}

\begin{abstract}
Resumo: Diferindo das correntes teóricas convencionais de interpretação da formação socioespacial dos países latino-americanos, que enfatizam o papel do capital comercial na transição ao capitalismo, Ignácio Rangel elabora uma teoria original que supera visões generalizantes deste processo, sendo capaz de identificar como se combinam dialeticamente diferentes modos de produção em uma unidade de contrários, em meio a sua dupla determinação (interna e externa) e, deste modo, como se comporta o universal em suas manifestações particulares. À luz do pioneirismo teórico de Rangel, o presente artigo busca identificar o processo histórico de constituição do que chamamos de dualidade básica da economia mexicana, uma construção que absorve elementos da estrutura de organização social dos povos précolombianos, da coroa feudal ibérica e de seu capital comercial, para gerar uma síntese dual.
\end{abstract}

Palavras-chave: Formação Socioespacial, Dualidade Básica, Ignácio Rangel.

\section{SOCIOSPATIAL FORMATION AND THE BASIC DUALITY OF THE MEXICAN ECONOMY}

\begin{abstract}
Unlike the conventional theoretical currents of interpretation of the sociospatial formation of Latin American countries, which emphasize the role of commercial capital in the transition to capitalism, Ignácio Rangel elaborates an original theory that overcomes generalizing views of this process, being able to identify how they are combined dialectically different modes of production in a unit of opposites (the sociospatial formation), in the midst of its double determination (internal and external) and, in this way, how the universal behaves in its particular manifestations. In the light of Rangel's theoretical pioneering spirit, this article seeks to identify the historical process of constituting what we call the basic duality of the Mexican economy, a construction that absorbs elements of the structure of social organization of the pre-Columbian peoples, the Iberian feudal crown and its commercial capital, to generate a dual synthesis.
\end{abstract}

Keywords: Socio-spatial formation, Basic Duality, Ignácio Rangel.

\section{INTRODUÇÃO}

Por muito tempo teve-se como objeto de estudo da geografia a relação sociedade/natureza. No entanto, este princípio comumente resultava em uma leitura dualista da realidade, tratando sociedade e natureza como elementos dissociáveis, separados. É através do materialismo histórico, enquanto teoria que considera tanto

\footnotetext{
${ }^{1}$ Mestrando do Programa de Pós-Graduação em Geografia da UFSC. E-mail: jvsandri09@ gmail.com.

${ }^{2}$ Professor Titular do Departamento de Geociências da UFSC. E-mail: ibastos57@gmail.com.
} 
a relação homem/homem (relações de produção) quanto a relação homem/natureza (forças produtivas), que se começa a superar dita antinomia e tratar estes dois elementos como uma unidade dialética, na medida em que o homem, ao transformar a natureza através de seu trabalho, transforma a si mesmo (PEREIRA, 2009).

A despeito da mesma raiz filosófica (a filosofia clássica alemã de Kant e, sobretudo, de Hegel), o encontro entre marxismo e geografia tardou a acontecer, uma vez que o primeiro nasceu mais internacionalista e o segundo mais nacionalista por surgir, enquanto ciência, em meio ao processo de unificação nacional alemã (MAMIGONIAN, 1996). No entanto, este cenário muda com Lênin, a partir da virada do século XIX para o XX, quando o capitalismo se desenvolve ao seu estágio superior, o capitalismo monopolista/imperialista. O revolucionário russo reformula e aprofunda a categoria de Formação Econômico-Social (FES), analisando o desenvolvimento desigual e combinado do capitalismo na Rússia (1977) e nos Estados Unidos (1980). Deste modo, é através das formulações leninianas em torno da categoria de Formação Econômico-Social ${ }^{3}$, que encontramos a mais sólida união entre marxismo e geografia, o que se fortaleceu, posteriormente, com a categoria miltoniana de Formação Socioespacial.

Partindo da categoria de formação socioespacial (ou formação econômicosocial) e problematizando o foco exacerbado no processo de circulação dissociado da formação de estruturas produtivas propriamente capitalistas, o artigo em questão busca resgatar o pensamento leninista do economista brasileiro Ignácio Rangel e verificar a validade de sua Teoria da Dualidade Básica enquanto fundamentação teórico-metodológica de análise da formação socioespacial do México.

\section{A CATEGORIA DE FORMAÇÃO SOCIOESPACIAL}

Por meio da análise da evolução histórica de diversos países e regiões, Karl Marx (2008) observou a existência de leis de desenvolvimento comuns a todos eles. Destacando as relações de produção (relação homem - homem) e as forças produtivas (relação homem - natureza), o intelectual alemão caracterizou os modos de produção comunistas primitivos, escravistas, feudais, capitalistas e socialistas. Importante destacar o papel dos meios fundamentais de produção - aqueles que subordinam todos os demais - como critério de classificação, a saber: 1) modo de produção escravista - o escravo; 2) modo de produção feudal - a terra; 3) modo de produção capitalista - capital ${ }^{4}$.

No entanto, como enfatizou Trotsky posteriormente, "o desenvolvimento de uma nação historicamente atrasada conduz, necessariamente, a uma combinação original das diversas fases do processus histórico. A órbita descrita toma, em seu conjunto, um caráter irregular, complexo, combinado" (TROTSKY, 1977, p. 25). É a partir dessa constatação de que o desenvolvimento se dá de forma desigual e

\footnotetext{
${ }^{3}$ Segundo Lênin (2020, p. 73), "a análise das relações sociais materiais (isto é, daquelas que tomam forma sem passar pela consciência do homem: quando trocam produtos, os homens entram em relações de produção sem sequer perceber que há uma relação social de produção aqui) - a análise das relações sociais materiais pela primeira vez tornou possível observar a recorrência e a regularidade, e generalizar os sistemas dos vários países em um único conceito fundamental: a formação social. Foi somente essa generalização que possibilitou proceder da descrição dos fenômenos sociais (e sua avaliação do ponto de vista de um ideal) para sua análise estritamente científica, que isola, digamos, a título de exemplo, aquilo que distingue um país capitalista de outro, e investiga o que é comum a todos eles".

${ }^{4}$ Segundo Ignácio Rangel (2005b, p. 631): "Ponto de parte o primeiro e o último dos modos fundamentais de produção, dado que, em ambos o corpo social comanda todos os fatores de produção, nos demais a hegemonia cabe à classe detentora do domínio do fator objetivamente estratégico. E é isso o que caracteriza o modo de produção e a formação social que sobre ele se edifica". Para uma maior explicação sobre isso, ver RANGEL, (2005a [1957])
} 
combinada que se evidencia a importância da categoria de formação social, ou formação econômico-social (FES).

Mesmo Marx (1991, p. 131) não se debruçando profundamente sobre esta categoria, embriões de seu fundamento se encontram, por exemplo, na passagem em que faz uma analogia com a estratificação da estrutura geológica do planeta Terra:

A formação arcaica ou primitiva do nosso globo contém uma série de estratos de diversas eras, uns sobrepostos a outros. Da mesma maneira, a formação arcaica da sociedade revela uma série de tipos diferentes, que caracterizam épocas diferentes e sucessivas.

Como o acontecer no espaço não se dá de forma homogênea, impõe-se a noção de escala, isto é, de fração do espaço dentro do espaço total. Isto não quer dizer que o acontecer em um lugar é indiferente ao acontecer em um outro lugar, justamente porque, qualquer que seja este acontecer, ele sempre será produto do movimento da sociedade total. Conforme Santos (2012, p. 208):

O espaço total e o espaço local são aspectos de uma única e mesma realidade - a realidade total — à imagem do universal e dos particulares. A sociedade global e o espaço global se transformam através do tempo, num movimento que, embora interessado igualmente às diversas frações da sociedade e do espaço, é o resultado da interação entre sociedade global e espaço global e de suas diversas frações".

A ideia de totalidade é central ${ }^{5}$, bem como a necessidade de sua cisão. Tratase de entender o movimento da totalidade como integral e diferencial: "Enquanto integral, a totalidade é vista como algo uno e, frequentemente, em abstrato. Enquanto diferencial, ela é apreciada em suas manifestações particulares, [...] em concreto" (Ibidem, p. 122) 6 . Deste modo, a totalização universal, que é dada pelo presente modo de produção, não pode realizar-se (no sentido de materialização ou objetivação) senão através de uma outra totalização que nos é fornecida por intermédio do conceito de formação social (SANTOS, 2012, p. 213). Justamente porque o tempo do modo de produção é universal, a categoria de formação social busca analisar como se arranja de forma concreta os diferentes modos de produção num espaço particular em seu desenvolvimento desigual e combinado. O modo de produção, com isso, é a possibilidade de realização, e a formação social, a possibilidade realizada.

Sereni, autor que se debruçou sobre a evolução da categoria de formação social, afirma que "esta categoria expressa a unidade (e, agregaremos, a totalidade) das diferentes esferas: econômica, social, política e cultural da vida de uma sociedade; e a expressa, além disso, na continuidade e ao mesmo tempo na descontinuidade de seu desenvolvimento histórico" (SERENI, 2013, p. 314-15).

\footnotetext{
${ }^{5}$ A ideia de totalidade, herança da filosofia de Hegel, é algo notável em Humboldt, sempre preocupado com relação do todo com as partes. Segundo Mamigonian (1996, p. 200): "Humboldt costumava dizer 'amo o que compreendo, o que abarco em sua totalidade'. Sua formação lhe permitia ver, segundo suas palavras, a natureza 'como um todo movido e animado por forças internas' e afirmar que 'o descobrimento da verdade é inconcebível sem a divergência de opiniões"'. A influência hegeliana também se vê em Lênin (2018, p. 122), em seus cadernos filosóficos sobre Hegel, quando afirma que "a coisa em si, no todo, é uma abstração vazia, sem vida. Na vida, no movimento, tudo acontece tanto 'em si' como 'para outros', na relação com o outro, transformando-se de um estado em outro".

${ }^{6}$ Segundo Milton Santos (2017, p. 120) "O todo somente pode ser conhecido através do conhecimento das partes e as partes somente podem ser conhecidas através do conhecimento do todo. Essas duas verdades são, porém, parciais. Para alcançar a verdade total, é necessário reconhecer o movimento conjunto do todo e das partes, através do processo de totalização".
} 
Entendemos que a categoria atinge maior maturidade com Milton Santos, quando se é atribuído com maior solidez o papel do espaço na estruturação e evolução da sociedade ${ }^{7}$, denominando-o de formação socioespacial, uma vez que "todos os processos que juntos formam o modo de produção (produção propriamente dita, circulação, distribuição, consumo) são histórica e espacialmente determinados num movimento de conjunto" (SANTOS, 1979, p. 14).

Conforme Armen Mamigonian (1996, p. 204),

Milton Santos, no entanto, percebeu que formação social e geografia humana não coincidem completamente, menos pelas teorias que embasam aquela categoria marxista e esta área do conhecimento acadêmico do que pela prática indispensável de localização da geografia, nem sempre usada nos estudos de formação social, daí ter proposto a categoria 'formação socioespacial'.

Em síntese, as formações socioespaciais existem "por causa de seus aspectos concretos que permitem levar em conta a especificidade de cada sociedade (sua evolução particular, sua situação atual, suas relações internas e externas)", bem como deve ser entendida como "uma realidade historicamente determinada fundada sobre uma base territorial" (SANTOS, 2012, p. 237-38). A visão de totalidade é central na análise das formações socioespaciais, na medida em que permite relacionar a interdependência entre os elementos da realidade, a dialética universal/particular e a unidade da história em meio ao desenvolvimento desigual e combinado dos diferentes espaços particulares. Por tudo isso, entendemos a categoria de formação socioespacial como o ponto de encontro entre a geografia e a economia política, e um referencial essencial nas investigações geográficas (JABBOUR, 2012).

\section{FORMAÇÃO SOCIOESPACIAL OU SISTEMA MUNDO?}

Em contraposição à categoria de formação socioespacial temos a corrente teórica do "sistema-mundo", matriz da Teoria da Dependência, e julgamos ser importante fazer alguns apontamentos a fim de demarcar diferenças fundamentais entre ambas e que influenciam profundamente a análise da realidade.

Partindo da premissa de que o lugar ocupado por determinado país no mundo depende sobremaneira da dinâmica do "sistema-mundo", que, por sua vez, tem grande impacto no desenvolvimento interno de cada nação, a perspectiva do "sistema-mundo" enfatiza fortemente as externalidades ${ }^{8}$. Deste ponto de vista, a própria análise da totalidade se torna débil ${ }^{9}$, pois:

\footnotetext{
${ }^{7}$ O espaço para Milton Santos é uma estrutura subordinada-subordinante, uma inércia-dinâmica. Isso significa dizer que, do ponto de vista de suas qualidades funcionais, o espaço representaria o reflexo da intencionalidade da sociedade sobre ele. Porém, do ponto de vista de suas qualidades sistêmicas, o espaço seria um condicionante das demais estruturas sociais (SANTOS, 2012, pp. 180-181). O espaço, portanto, não é somente um mero palco da atividade humana, mas sim uma união dialética entre sociedade e natureza, indissociáveis entre si.

8 Para uma crítica à perspectiva do sistema-mundo, ver: JABBOUR, Elias. O Ponto de Encontro entre a Geografia e a Economia Política na Categoria de Formação Social. In: China hoje: projeto nacional, desenvolvimento e socialismo de mercado. 1a ed. São Paulo : Anita Garibaldi : Fundação Maurício Grabois : EDUEPB, 2012.

${ }^{9}$ Sobre estas análises estáticas e fotográficas de "modelos" econômicos, que apenas vêem o todo pelo todo, e não na dinâmica de suas manifestações particulares, Hobsbawm (1991, p. 63) comenta: "Assim, o desejo de classificar cada sociedade ou período, firmemente, em uma ou outra das categorias aceitas deu como resultado disputas demarcatórias, como é natural quando se insiste em encaixar conceitos dinâmicos dentro de estáticos. Houve, deste modo, muita discussão na China sobre a data da transição da escravidão ao feudalismo desde que 'a luta foi de natureza muito prolongada, cobrindo vários séculos... Modos de vida sociais e econômicos diversos coexistiram temporariamente no amplo território da China'. No ocidente,
} 
De um lado, a ideia de totalidade-mundo é reduzida a um dos seus aspectos e, de outro, o enfoque adotado conduz, geralmente, a análises externas ao fato geográfico, este ficando subjugado por alusões, comparações, analogias, metáforas, que, em nenhum caso, substituem a visão constitutiva do fenômeno. (SANTOS, 2017, p. 114)

Os autores ligados a esta corrente tendem a conceber o capital comercial como o principal elo de transição ao capitalismo, inclusive crendo na existência de um capitalismo consolidado na Europa pelo menos 200 anos antes da Revolução Puritana. Maurice Dobb, notável intelectual que se debruçou sobre o tema da transição feudalismo-capitalismo, chama a atenção para a forma como essa nova burguesia mercantil entrou em "acordo com a sociedade feudal, assim que seus privilégios foram conquistados". Nesse sentido, "o grau em que o capital mercantil floresceu num país nesse período não nos proporciona medida alguma da facilidade e rapidez com que a produção capitalista estava destinada a se desenvolver", e completa, "em muitos casos deu-se exatamente o contrário" (1987, p. 127). Sobre o papel do capital comercial no desenvolvimento do capitalismo, Lênin (1977, pp. 18384) é muito claro quando diz que:

[...] historicamente, o capital comercial e usurário precede a formação do capital industrial e é, logicamente, a sua condição necessária, embora não a suficiente para o seu aparecimento (ou seja: para o aparecimento da produção capitalista); de fato, o capital comercial e usurário nem sempre decompõem o antigo modo de produção, substituindo-o pelo modo de produção capitalista: a formação deste último 'depende inteiramente do grau de desenvolvimento histórico e das suas circunstâncias'. 'A profundidade da decomposição do antigo modo de produção [pelo comércio e pelo capital comercial] depende, antes de tudo, da sua solidez e da sua estrutura interna. Não é do comércio, mas do caráter do antigo modo de produção que depende o resultado do processo de dissolução, ou seja, o modo de produção novo que ocupará o lugar do antigo'. 3) o desenvolvimento independente do capital comercial é inversamente proporcional ao nível de desenvolvimento da produção capitalista: mais o capital comercial e usurário se desenvolve, menos o faz o capital industrial (= a produção capitalista), e vice-versa.

Tendo em vista a primazia da produção, torna-se necessário a distinção entre o processo de inserção da periferia com o sistema capitalista e a formação de estruturas econômicas próprias do capitalismo moderno, tendo em vista que o primeiro não suscitou necessariamente o surgimento imediato do segundo, bem como aponta Eric Hobsbawm (2017, p. 106). Deste modo, as teorias do "sistema-mundo", ao entender a fase do capitalismo comercial como um capitalismo consolidado, consideram capitalista "[...] qualquer país que mantenha relações comerciais na esteira do mercado mundial unificado capitalista, independente das formas de produção internas em cada país", sendo portanto, o "suprassumo da negação do processo como ente histórico/filosófico e, consequentemente, da categoria de modo de produção" [grifo do autor] (JABBOUR, 2012, p. 92). Cabe fazermos a pergunta que Ellen Wood (2014, p. 132):

dificuldade semelhante conduziu a debates sobre o caráter dos séculos que vão do XIV ao XVIII. Estas discussões tiveram, ao menos, o mérito de levantar os problemas da mistura e coexistência de diferentes "formas' de relações sociais de produção". 
Se o fator decisivo é a acumulação de riqueza comercial, por que a Inglaterra? Por que a transição inglesa para o capitalismo ocorre no momento em que a Inglaterra estava longe de ser o país mais rico dos principais países europeus, ou mesmo o maior ou o mais forte, e possuía acumulações muito mais limitadas de riqueza comercial? 0 que explica a emergência do capitalismo agrário na Inglaterra antes e, de fato, como condição - de sua supremacia comercial posterior?

O grande problema desta análise é que parece não haver nenhuma diferença essencial entre o capitalismo e outras formas de comércio, e desta forma tornar-se-ia "difícil entender porque não se poderia dizer que algum tipo de capitalismo, ou protocapitalismo, existiu, ao menos de modo embrionário, na Roma antiga (como sugere Max Weber)" (WOOD, 2014, p. 131). Assim,

O capitalismo, nessa concepção, não tem lógica ou dinâmica definida que o diferencie com clareza das outras formas sociais. Em particular, os imperativos específicos da concorrência capitalista, suas regras típicas de reprodução - a necessidade de estratégias de maximização, a maximização do lucro, e a necessidade constante de melhoria da produtividade no trabalho -, não são, aparentemente, essenciais para a definição do capitalismo. Elas não operavam, por exemplo, no caso genovês, no espanhol, nem no português. ${ }^{10}$

Nota-se que existe uma confusão entre economia mercantil e capitalismo, desconsiderando que, conforme Marx (1991, p. 106), "a formação da riqueza monetária, em si, antes da transformação em capital: isto pertence à pré-história da economia burguesa". Ou seja, o capitalismo pressupõe uma economia mercantil, mas nem todas as economias mercantis são capitalistas, uma vez que o modo de produção capitalista somente se estabelece quando esta economia mercantil se encontra em sua etapa de desenvolvimento em que torna-se mercadoria até mesmo a força de trabalho, como fica evidente no capítulo XXIV d'O Capital (2017), em $A$ Assim Chamada Acumulação Primitiva. Esse erro faz com que a análise se aproxime muito mais de Adam Smith do que ao do próprio Marx, na medida em que o problema histórico das origens do capitalismo torna-se o das origens da divisão social do trabalho baseada no comércio, e não o de uma transformação social peculiar, como pensava Marx. (BRENNER, 1977, pp. 39-40).

Por fim, sobre esta polêmica, aprendemos com Lênin que a grande extensão territorial das explorações nada tem a dizer sobre o caráter capitalista ou não dela:

O exemplo americano mostra-nos com evidência como seria imprudente confundir os latifúndios com a agricultura capitalista em grande escala, pois, com muita frequência, os latifúndios constituem uma sobrevivência de relações pré-capitalistas: escravistas, feudais ou patriarcais (LÊNIN, 1980, p. 42).

Isto porque o que indica o desenvolvimento do capitalismo na agricultura é sobretudo o "volume dos investimentos de capital na terra" isto é, "modificações técnicas introduzidas na agricultura, sua intensificação, a passagem a sistemas superiores de cultura, a utilização massiva de adubos artificiais, o aperfeiçoamento

${ }^{10}$ Ibidem, p. 131. 
dos instrumentos e máquinas", além, é claro, do "recurso crescente ao trabalho assalariado". Portanto, se considerarmos apenas a superfície, "não é possível expressar todos estes processos complexos e diversos, quando é precisamente o seu somatório que caracteriza o processo geral do desenvolvimento do capitalismo na agricultura" (LÊNIN, 1980, pp. 52-3).

Em suma, é através do deslocamento da análise do processo produtivo para o processo de circulação que opera o erro das perspectivas circulacionistas do sistemamundo, muito populares na América Latina com a chamada Teoria Marxista da Dependência.

\title{
A TEORIA DA DUALIDADE BÁSICA
}

Apesar de ser reconhecido como "provavelmente o mais original analista do desenvolvimento econômico brasileiro" por Bresser-Pereira e José Marcio Rego (2014, p. 122), bem como por Ricardo Bielschowsky (2004, p. 209), Ignácio Rangel é praticamente ignorado na academia e no debate político brasileiro. Sua criatividade é fruto de uma formação intelectual eclética, que combina desde a filosofia clássica alemã de Kant e Hegel, até Smith, Marx, Lênin, Schumpeter e Keynes (Jabbour, 2017, pp. 561-583).

Rangel entendia que era necessário assimilar de forma crítica as teorias convencionais elaboradas nos países do centro do sistema, dado que a história do Brasil "não retrata fielmente a história universal, especialmente a europeia, porque nossa evolução não é autônoma, não é produto exclusivo de suas forças internas" (RANGEL, 2005a, p. 296). Essa dupla determinação, interna e externa, produz uma dualidade estrutural na economia e na sociedade brasileira. Deste modo, o que ocorria era uma "coexistência de relações de produção próprias de diferentes modos fundamentais de produção, agrupadas em 'polos' - interno e externo - em união dialética, isto é, em oposição e conflito” (RANGEL, 2005b, p. 633). Em outras palavras,

\begin{abstract}
[...] a coexistência da realidade "antiga" com a "nova" - a contemporaneidade do não coetâneo, por assim dizer - não é uma simples superposição, mas uma oposição. As duas realidades reagem uma sobre a outra e se modificam mutuamente. Além disso, não constituem duas coisas separadas, mas uma realidade complexa única. Para usar a linguagem hegeliana, os contrários estão em unidade dialética. (RANGEL, 2005a, p. 207)
\end{abstract}

Durante o período de expansão comercial em que inicia-se as colonizações, o capital comercial incorporou o papel de articulador entre o centro e a periferia, e assim "as formações sócio-espaciais periféricas eram compostas de dois setores: o capital mercantil europeu presente na colônia e na metrópole e as estruturas produtivas internas que sozinhas não conseguiam definir um modo de produção" (MAMIGONIAN, 2000, pp. 23-24). Essas unidades produtivas eram organizadas sob um enquadramento jurídico e econômico feudal, pois ligado à Corôa europeia ${ }^{11}$, tendo ainda no Brasil um conteúdo pré-feudal (escravista), por conta do baixo desenvolvimento das forças produtivas dos povos originários nômades, baseado no

\footnotetext{
${ }^{11}$ Evidenciando o caráter feudal dos Estados colonizadores ibéricos, não é de se surpreender que o “o próprio desenvolvimento do capitalismo em escala mundial gerou ou regenerou em vários lugares e em vários momentos relações sociais dependentes que não são capitalistas" (HOBSBAWM, 2017, p. 106).
} 
comunismo primitivo, diferentemente da América espanhola onde as civilizações já eram sedentárias e hierárquicas. Com isso, a dualidade se forma na América Latina em uma unidade dialética entre as relações de produção internas (da unidade produtiva) e as relações de produção externas (capital comercial) ${ }^{12}$.

No entanto, é importante fazermos uma distinção metodológica entre a dualidade básica de Ignácio Rangel e o dualismo estruturalista da CEPAL. O dualismo cepalino diz respeito a uma oposição entre um setor arcaico e um moderno, sendo uma oposição que se reproduz continuamente, afastando cada vez mais ambos setores econômicos um do outro. Esses setores, por vezes, se expressam geograficamente através de um campo atrasado e uma cidade moderna. A dualidade rangeliana, por outro lado, diz respeito ao processo de endogeneização do capitalismo na formação social brasileira, processo esse que implica um longo período de coexistência de diferentes modos de produção em uma mesma formação social.

\section{AS BASES FUNDAMENTAIS DA FORMAÇÃO SOCIOESPACIAL DO MÉXICO}

O México é um país com uma profunda diversidade, tanto no que diz respeito ao seu meio físico e biológico (relevo, clima, vegetação, etc), quanto ao meio econômico-social (étnico-racial, cultural, desigualdade econômica, etc.). É através das múltiplas determinações originadas destas combinações geográficas (CHOLLEY, 1964), que vai se delineando a formação socioespacial mexicana. Comecemos pelo período pré-colonização.

\section{ASPECTOS FÍSICOS E OS POVOS ORIGINÁRIOS}

É inegável o papel das condições físicas do México na conformação do caráter heterogêneo e desigual do seu desenvolvimento social, sobretudo em suas etapas iniciais. $O$ grande número de montanhas contribuiu para distribuir a população em uma sucessão de vales e planaltos, separados entre si por serras que dificultam a comunicação e favorecem o isolamento. Ao oeste, localiza-se a maior cadeia de montanhas do país, conhecida como Sierra Madre del Occidental, com grande número das minas exploradas pelos espanhóis. Ao leste temos a Sierra Madre Oriental, contornando a costa do Golfo do México. E ao sul, virada para a costa do Pacífico, está presente a Sierra Madre del Sur, onde se encontra o ponto com maior altitude do território mexicano, o Pico de Orizaba, com 5.636 metros. Em toda a porção central do país se estende um longo planalto que vai se tornando cada vez mais desértico ao norte. No extremo sul, na península de Yucatán, predominam as planícies (Mapa 1).

Antes dos europeus, a região onde hoje é o México era um "mosaico étnico" de mais de 600 grupos indígenas, falando 80 línguas pertencentes a 15 famílias linguísticas diferentes. Esse conjunto de povos originários poderiam ser divididos em dois grupos: a população nômade dedicada à coleta, caça e pesca; e as grandes civilizações sedentárias. A distribuição geográfica destes dois grupos era estabelecida com relativa nitidez, podendo ser delineada próxima ao paralelo 19 Norte. Na região setentrional, ao norte, mais árida e desértica, com predomínio de

\footnotetext{
12 Em consonância com Ramos (2019) e Autor (2014), entendemos a Dualidade Básica como tendo enorme potencial de representar a teoria e o método de análise das formação sociais periféricas.
} 
estepes, situavam-se as populações nômades, espalhadas e pouco numerosas. Já ao sul, na região meridional, nos vales e planaltos entre a Sierra Madre Oriental e del Sur, bem como nas planícies da península de Yucatán, encontravam-se as civilizações sedentárias, mais numerosa e cuja organização era mais complexa (SEMO, 1987).

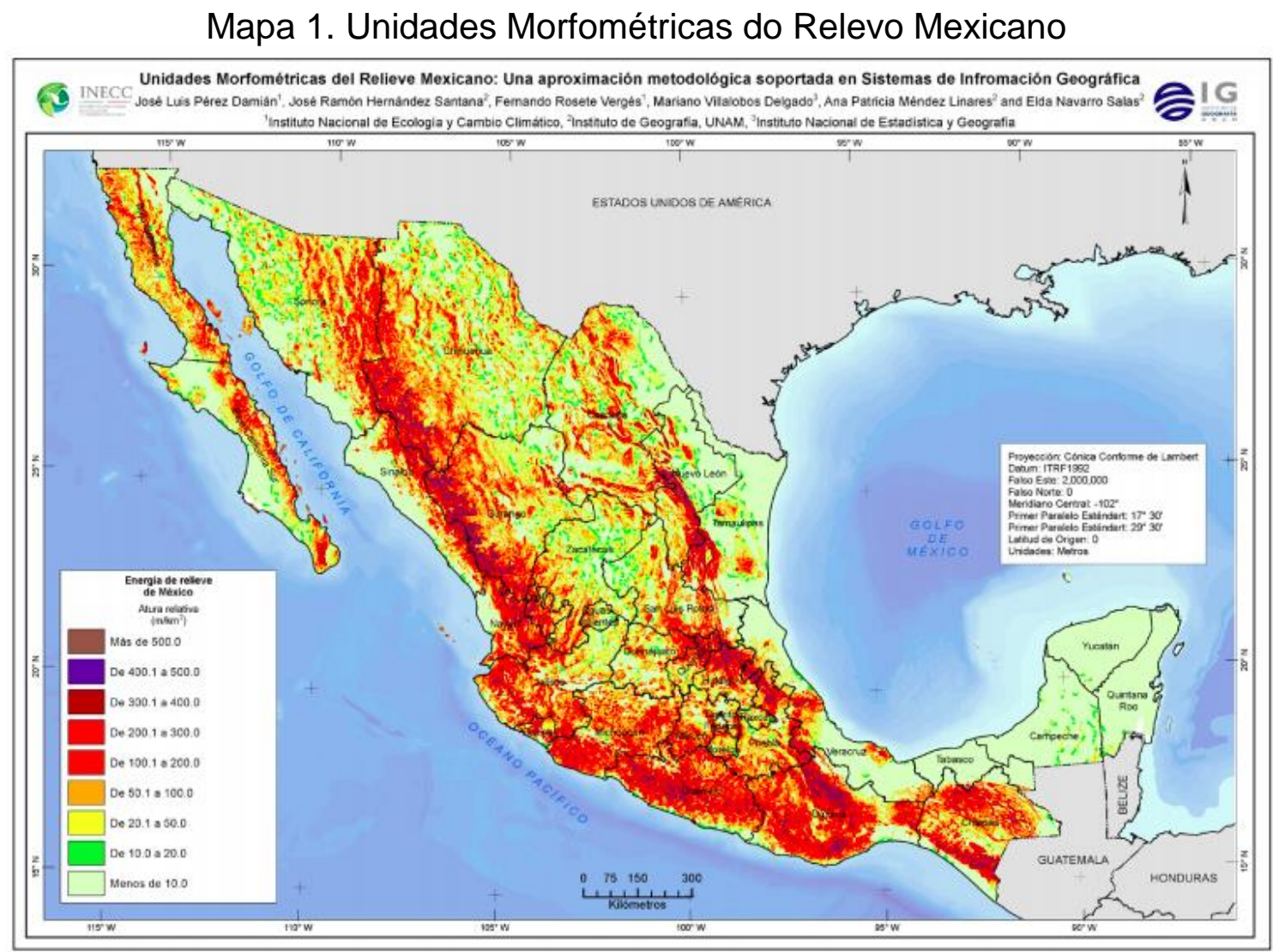

Fonte: Santana et al. (2017)

Os nômades do Norte não conheciam nenhum cultivo, se alimentavam de frutas, tubérculos e, com seus arcos e flechas, caçavam veados, coelhos e outros animais pequenos. Com raras exceções, não tinham templos nem deuses, apenas adoravam o sol (CHEVALIER, 1956). Contraste profundo com a região meridional. Nesta, grandes civilizações complexas e sedentárias floresceram, como a civilização asteca, maia e o Estado de tarasco. A base da alimentação desses povos era o milho, algo que guarda grande influência até os dias de hoje. $O$ feijão e a abóbora completavam a dieta diária, a qual se adicionava eventualmente tomate, abacate, melão, banana e abacaxi, sendo a bebida preferida o cacau. Cultivava-se algodão nas zonas baixas, o qual era usado para confeccionar vestes para a classe dominante oriunda do aparelho do Estado. Devido à falta quase total de animais para domesticação, estes povos não utilizavam no planalto mais do que as áreas férteis e bem irrigadas, concentrando a ocupação nos vales das bacias fluviais (SEMO, 1987).

No momento da chegada dos espanhóis, existiam dois grandes Estados: 0 asteca, mais ao leste; e o Estado de Tarasco, ao oeste, onde hoje se encontra o estado de Michoacán, sendo o império asteca muito maior, mais rico e mais poderoso em comparação a este último. Em sua expansão, não impunha aos povos vencidos seu governo, idioma ou religião, exercendo seu domínio apenas por vias tributárias. 
O Estado de Tarasco, por outro lado, criou colônias com sua própria gente nas zonas conquistadas, estendendo sua influência linguística e cultural. Os maias haviam vivido seu auge entre os anos 300 d.C. e 900 d. C., mas a partir do século $X$ iniciaram um longo período de decadência, subsistindo daí em diante de forma precária na parte norte de Yucatán (Ibidem, p. 21-22)

O império asteca, o mais importante da época, possuía uma estratificação social bem marcada entre os nobres ou senhores (pilli) e os membros do calpulli (macehuales ou calpuleques), uma espécie de clã. A origem dessa aristocracia se encontra na descendência dos antigos ocupantes do vale do México, já o desenvolvimento do calpulli está vinculada a expansão militar dos astecas (CHEVALIER, 1956). As formas de propriedade da terra constituíam-se em três: 1) as terras do calpulli, que se dividiam entre as terras de cultivo de cada linhagem ou grupos de famílias e as terras comunais; 2 ) as propriedades dos nobres, individual, alienável entre eles com certas restrições e transmissível por herança; 3) diversos tipos de propriedades públicas, cujos produtos eram destinados à casa real, aos templos, à atividade de guerra e aos gastos administrativos (CARDOSO e BRIGNOLI, 1984).

Em relação ao trabalho, existiam quatro tipos básicos de trabalhadores: 1) os membros do calpulli, que trabalhavam para seu autoconsumo e para o pagamento de tributo, além da possibilidade de arrendar partes da terra para terceiros; 2) os arrendatários, que trabalhavam terras alheias (de nobres ou de comunidades); 3) os mayeques, uma espécie de servo exclusivo de alguns nobres, arrendatários também mas presos à terra; 4) os escravos, que trabalhavam em circunstâncias semelhantes aos dos mayeques (CARDOSO e BRIGNOLI, 1984; CHEVALIER, 1956).

O intercâmbio havia alcançado um nível importante, sobretudo entre as regiões do planalto/vale do México com as zonas tropicais das planícies litorâneas, que por suas peculiaridades edafoclimáticas produziam mercadorias muito diferentes, formando uma complementaridade em que o primeiro fornecia a maior parte dos produtos de alimentação (milho, feijão, pimenta, etc.) e o segundo produzia o cacau e o algodão (CARDOSO e BRIGNOLI, 1984, p. 51).

Com o início da colonização, portanto, o México era dividido entre a região setentrional, marcada pelo clima desértico e as tribos nômades mais hostis ao domínio europeu, e a região meridional, com a predominância dos vales e planícies férteis e de civilizações complexas, estratificadas e que já dominavam o cultivo da terra.

\section{COLONIZAÇÃO ESPANHOLA E ORGANIZAÇÃO TERRITORIAL}

Desde fins da Idade Média, havia se desenvolvido na Espanha uma classe de comerciantes que viriam a promover as chamadas "Grandes Navegações", a partir do final do século XV, em conjunto com a Coroa espanhola. Esta nova classe se aliou aos antigos senhores de terra de tal modo que, "ao não desenvolver-se a manufatura local (exceto em Segóvia), a burguesia espanhola permaneceu como um addendum parasitário da nobreza feudal" (CARDOSO e BRIGNOLI, 1984, p. 29). Essa estrutura econômica espanhola se mantém com ainda mais força a partir da comercialização da prata americana, o que "inflacionou a estrutura de preços vigente no país de forma mais acelerada e profunda que sobre seus parceiros comerciais, levando à ruína as poucas indústrias que se haviam desenvolvido no período anterior" (STEIN e STEIN, 1977 , p. 21). A classe latifundiária sai fortalecida dessa relação, enquanto que a 
burguesia comercial se vê acomodada ao sistema senhorial de dominação, se favorecendo dele. Segundo Stanley e Barbara Stein:

A herança medieval não parecia constituir empecilho algum à expansão espanhola antes de 1500; afigurava-se, ao contrário, como fator de unidade e crescimento. A exploração das colônias americanas, México e Peru, tornara desnecessária a reestruturação de uma Espanha caracterizada pela prevalência de estruturas econômicas e sociais semifeudais, baseadas na posse da terra e aristocráticas. Não se trata, pois, de uma simples atrofia: em verdade, se os setores produtivos essenciais contraíram-se, determinados setores consumidores - a aristocracia, a burocracia, as ocupações voltadas para a prestação de serviços, a Igreja - floresceram. Nos anos que se seguem a 1600 os Estados europeus, modernizando-se, passam a questionar os conceitos e as práticas do privilégio, do 'Estado absoluto', da Igreja, do usufruto privado do poder público, do ouro e prata em lugar da produção, como fatores geradores de riqueza. $\mathrm{Na}$ Espanha e na América espanhola, não obstante, essas instituições e atitudes conheceram um novo revigoramento (Idem, 1977, pp. 24-25)

Os fulcros de capitalismo que surgem no seio da sociedade feudal espanhola, imprimiram certo dinamismo em sua economia, mas foi através do feudalismo que se organizou a colonização, tanto sob enquadramento jurídico quanto econômico. Em outras palavras, a "Europa tudo fez para enquadrar a América numa carapaça feudal", sendo o primeiro passo dessa empreitada o Tratado de Tordesilhas, "o qual, ao mesmo tempo que dividia o continente americano entre as coroas de Espanha e Portugal, estatuía que todas as nossas terras pertenciam ao rei" (RANGEL, 2005b, pp. 655-56). A Coroa espanhola logo impôs sua hegemonia ${ }^{13}$, de forma a derrotar "todas as tentativas - na Nova Espanha e no Peru - que fizeram os colonizadores de se tornar independentes de sua tutela e consolidou sua posição de proprietária imanente das terras, riquezas e homens do Novo Mundo"14 (SEMMO, 1987, p. 67, tradução nossa). Ao visitar o Vice-Reino da Nova Espanha, Humboldt aponta para esses elementos arcaicos de herança transmitida da metrópole à colônia:

se reconoce que á pesar de la diferencia de clima y otras circunstancias locales, la agricultura mejicana está llena de trabas por las mismas causas políticas que entorpecen los progresos de la industria en la península. Todos los vicios del gobierno feudal han pasado del uno al otro hemisferio; [...] El suelo de la Nueva-España, bien asi como el de la vieja, en gran parte se halla en poder de algunas familias poderosas que han absorvido lentamente las propiedades particulares. Tanto en América como en Europa, hay grandes distritos que están condenados á servir de pasto para el ganado y á una perpetua esterilidad (1827, p. $445-46) \cdot{ }^{15}$

\footnotetext{
${ }^{13}$ Segundo Stanley e Barbara Stein (1977, p. 22), "Esse comércio colonial [...] fora, desde o início, organizado de molde a assegurar o monopólio dos benefícios para a coroa, súditos e residentes de Castela. Controlado por uma Câmara de Comércio (Casa de Contratación) e uma guilda de comerciantes (Consulado), refletia o estreito exclusivismo das práticas comerciais características da etapa final da era medieval.

${ }^{14}$ Desse modo, a América espanhola fora considerada um grande feudo para a Coroa, conforme Semo (1987, p. 66-67): “Os conceitos de colônia e fábrica não aparecem na legislação espanhola dos séculos XVI e XVII, porque a casa reinante considerava suas imensas poses americanas como novos reinos ou repúblicas tributárias que viriam a agregar-se a constelação das já existentes na Espanha e fora dela e não como um objeto de exploração colonial pela nação espanhola".

${ }^{15}$ É reconhecido que, apesar da diferença de clima e outras circunstâncias locais, a agricultura mexicana está repleta de obstáculos devido às mesmas causas políticas que impedem o progresso da indústria na península. Todos os vícios do governo
} 
Pelo fato de que já existia um Estado consolidado antes da colonização, "o 'Estado missioneiro' espanhol não fez mais que substituir a teocracia indígena, enquanto que os conquistadores tomavam pouco a pouco o lugar da nobreza local" 16 (CHEVALIER, 1956, p. 26, tradução nossa). Deste modo, "a relação entre a Coroa e as comunidades indígenas veio a ser uma continuação dos elementos tributários da sociedade pré-cortesiana ${ }^{17}$ ", uma vez que a "visão de um império baseado no tributo de inumeráveis comunidades [...] incondicionalmente submetidas ao poder central, emana da essência mesma do Estado espanhol, tal como este era nos séculos XVI e XVII" (SEMO, 1987, p. 65).

A partir disso se estrutura a primeira forma de colonização, a encomienda ${ }^{18}$, que se constituía em uma "tarefa" oficial das comunidades indígenas a um colonizador. O encomendero devia assegurar a submissão dos indígenas, regular sua administração e convertê-los ao cristianismo. Em contrapartida, possuía o direito de receber o tributo dos indígenas. A encomienda não era uma propriedade e sim um usufruto. Os indígenas eram livres, vassalos do rei, mas não do encomendero. Esse último, ao invés de ser um empresário, era um aristocrata, um funcionário real, cujo modo de vida antes de chegar a ser burguês, tende rapidamente a se feudalizar (SEMO, 1987). Conforme Donghi (1974, pp. 12-13), os conquistadores e seus sucessores "orientaram-se predominantemente para a agricultura, sobretudo como encomenderos, dos quais deviam receber os tributos que, em todos os casos, os vassalos indígenas deviam à Coroa". Nesse sentido, até mesmo Furtado concorda que o "encomendero, em razão da tutela que exercia sobre um grupo de população, passava a exercer privadamente funções de direito público, o que o colocava socialmente em posição somente comparável à do senhor feudal" (FURTADO, 1978, p. 19).

Como cada encomendero recebia algumas centenas de vassalos ${ }^{19}$ indígenas, tornava-se difícil uma concentração muito grande de encomenderos em uma mesma vila ou cidade, de modo que estas condições propiciaram uma maior dispersão da população. Logo surgiram as primeiras cidades, predominantemente na região meridional, como Villa Rica de la Vera Cruz, Espiritu Santos (Coatzacoacos) e Santi Esteban de Puerto (Pánuco), sobre o Atlântico; Zacatula, Culiacán, Colima, Purificación e Compostela, na vertente do Pacífico; Antequera (Oaxaca), San Ildefonso (Villa Alta), Guadalajara. Cada cidade era constituída basicamente por uma praça, uma igreja e um conjunto de casas, e enraizada sob as tradições medievais. Nesse momento, o comércio ainda era ínfimo e as cidades eram autônomas (CHEVALIER, 1956).

O florescimento da atividade mineira foi de fundamental importância no processo de ocupação do território do país, bem como permitiu a manutenção da economia metropolitana espanhola. Em 1545, os espanhóis descobriram as minas de

\footnotetext{
feudal passaram de um hemisfério a outro; [...] O solo da Nova Espanha, assim como o da velha, está em grande parte nas mãos de algumas famílias poderosas que absorveram lentamente as propriedades particulares. Tanto na América como na Europa, existem grandes distritos condenados à pastagem para o gado e à esterilidade perpétua (tradução livre nossa).

16 “el 'Estado misionero' español no hizo más que sustituirse a la teocracia indígena, mientras que los conquistadores tomaban poco a poco el lugar de la nobleza local".

17 Hernán Cortés foi um conquistador espanhol, conhecido por ter conquistado a área central do México, antiga capital do império asteca.

18 Conforme Chevalier (1956), a encomienda americana era uma instituição muito semelhante a que já existia em Andaluzia, na própria Espanha.

19 Segundo Stanley e Barbara Stein (1977, p. 37), os espanhóis que buscavam o Novo Mundo "passaram à exploração das populações indígenas, colocando-as como vassalos da monarquia espanhola”.
} 
Zacatecas, mais ao norte do núcleo demográfico de herança asteca. Na medida em que novas minas foram sendo descobertas pelos espanhóis, concentradas no noroeste mexicano, mais claro ficava que o México mineiro era o México setentrional. Esse fato contribuiu para a ocupação da região semi-árida menos densamente povoada.

Esses centros mineiros que se formaram, chamados de reales de minas, não eram autônomos, pois dependiam de suprimento externo a eles. Portanto, concomitante ao seu surgimento, formaram-se também vastas áreas subsidiárias dedicadas as atividades agropastoris destinadas, em grande parte, a abastecê-los. Essas atividades foram impulsionadas, sobretudo, no caminho mina-capital-porto, formando uma corrente comercial abrangendo o centro de Jalisco e Michoacán, os vales meridionais de Zacatecas, de San Luis e do Bajío, os vales centrais de Oaxaca e na costa de Colima, Guerrero e Veracruz (BATALLA, 1979).

$O$ regime de trabalho nas minas variava entre o recrutamento de indígenas através do repartimiento, que predominava nas minas do centro-sul, enquanto que sistemas precoces de trabalho assalariado predominavam nas minas do centro-Norte. Cenário contrastante com a realidade laboral das minas do Vice-Reino do Peru, onde a coerção da população indígena para o trabalho mineiro gerou a mita (CARDOSO e BROGNOLI, 1984). Entendemos que o desenvolvimento da atividade mineira representou um capitalismo embrionário na formação socioespacial mexicana, ainda que a Coroa se considerasse proprietária do subsolo e concessionária das minas, cobrando o quinto das suas produções.

Durante os primeiros séculos de colonização, portanto, existiam dois tipos de cidades no Vice-Reino da Nova Espanha (cujo território pode-se visualizar no Mapa 2): as primeiras, que surgem nas regiões mais povoadas, herança das civilizações pré-colombianas, muito ligadas à estrutura despótico-tributária e com pouco desenvolvimento mercantil (com a exceção da capital, Cidade do México, com sua poderosa oligarquia mercantil); e as que surgem posteriormente, com a descoberta das minas e o crescimento da atividade mineira e agropastoril, cuja orientação mercantil era mais acentuada. Porém, as classes dominantes da cidade são as mesmas que as do campo: a burocracia vice-reinal, os encomenderos e os donos das minas (SEMO, 1987).

Desde o início da colonização, podemos dizer que a terra era o meio fundamental de produção, pois atribuía à quem a possuía poder econômico e político. Conforme Chevalier (1956, pp. 139-40):

Así como los 'ricos homes' de la vieja España eran caudillos y jefes más aún que capitalistas, así también es evidente que ciertos mineros y "señores de ganado" buscaban menos los bienes materiales por sí mismos que por el poder político que podían otorgarles. [...] Si cada quien extendía indefinidamente sus propiedades, no era tanto para aumentar sus ingresos, sino más bien para "señorear", según la expresión de la época: para ser dueño y señor de la región ${ }^{20}$

Essa tendência ociosa e senhorial dos proprietários fundiários no México permanecerá após a consolidação da hacienda, a qual abordaremos na próxima seção. Como vimos, já neste primeiro período colonial inicia-se a gestação da

\footnotetext{
${ }^{20}$ Assim como os "ricos homens" da velha Espanha eram caudilhos e patrões ainda mais do que capitalistas, também é evidente que certos mineiros e "senhores do gado" buscavam os bens materiais menos para si mesmos do que para o poder político que podiam lhes conceder. [...] Se todos estendiam suas propriedades indefinidamente, não era tanto para aumentar sua renda, mas sim para "señorear", segundo a expressão da época: ser dono e senhor da região (tradução livre nossa).
} 
dualidade básica da economia mexicana, por meio das relações feudais importadas da Coroa espanhola e adaptadas às heranças pré-colombianas, através das chamadas encomiendas e repartimientos, em íntima relação com o capital comercial espanhol, representado pelos comerciantes de importação e exportação ligados à Coroa, formando uma estrutura feudal-mercantil. Esta estrutura, com o tempo, sofre mudanças, tornando-se mais propriamente latifundiária, a partir do advento das haciendas. Nelas, a sujeição ao trabalho ganha novas formas, mantendo-se, no entanto, essencialmente feudais.

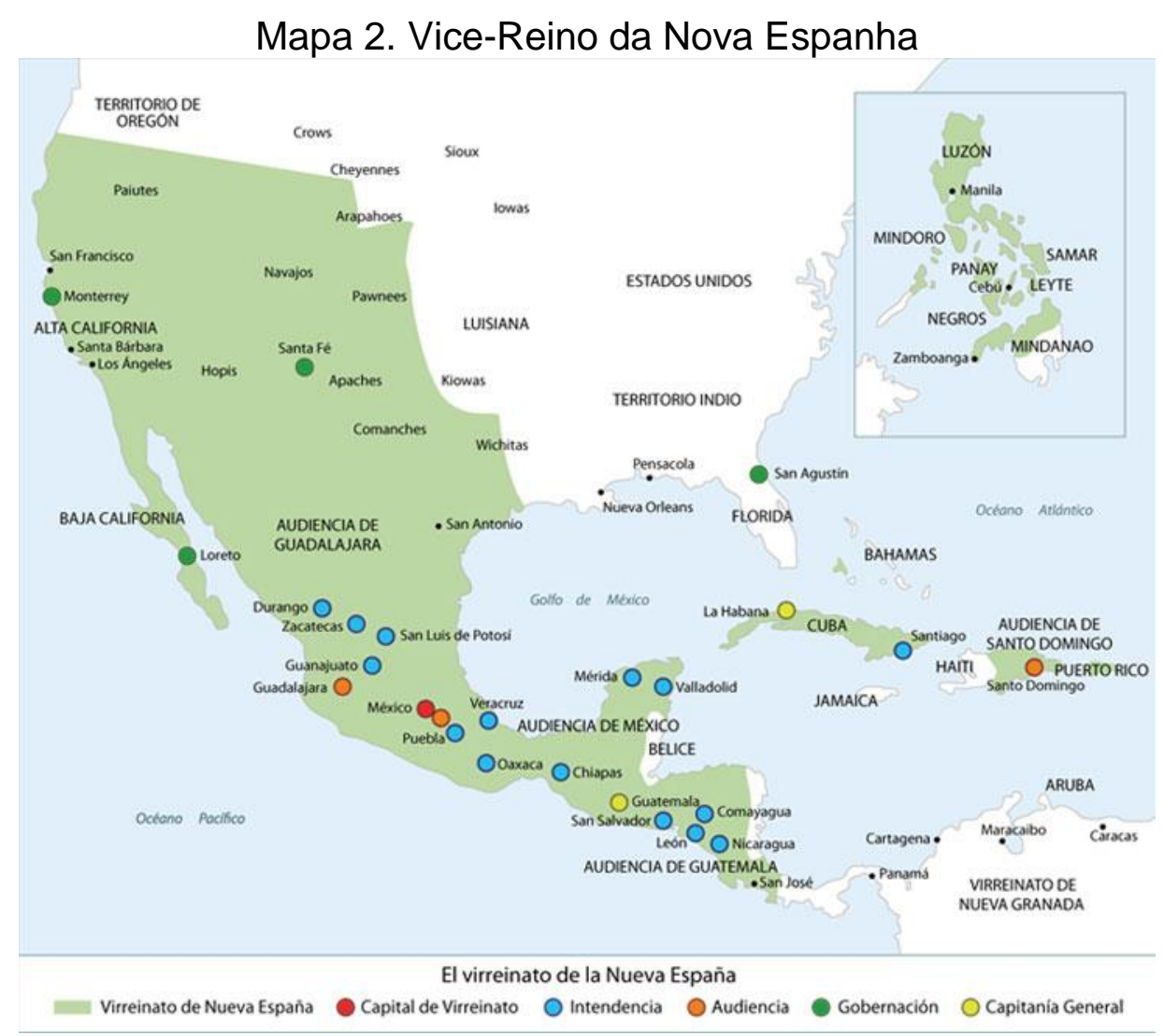

Fonte: Conocimientos Fundamentales, 2021

\section{A HACIENDA E O COMPLEXO RURAL}

Até finais do século $\mathrm{XVI}$, a propriedade da terra tinha um caráter impreciso e volátil. A maior parte das concessões atribuía apenas o direito ao uso da terra, fazendo-as dependentes do favor real e submetendo-as a fortes tributações fiscais. Somente a merced real que concedia o domínio privado da terra. A monarquia espanhola, passando por um período de dificuldades financeiras, vê a possibilidade de adquirir novos fundos através da regularização fundiária feita por meio do pagamento direto à coroa. É desta forma que se dá, no século XVII, a consolidação territorial dos latifúndios no México e a superação das antigas noções de direitos de uso e pasto comum para uma verdadeira propriedade do solo. Surgia, assim, a hacienda (CHEVALIER, 1956).

Um segundo fenômeno contribuiu para a aceleração da consolidação territorial: a decadência mineira. $O$ surto mineiro, que se iniciou na segunda metade do século XVI, foi intenso, mas não muito extenso do ponto de vista temporal. Cem anos depois da descoberta da primeira mina, a atividade vivia uma grande 
decadência, o que refletiu na economia colonial e metropolitana. Com isso, os proprietários das minas e comerciantes transferiram seus investimentos para a terra, o que acelerou a formação e a consolidação das haciendas (STEIN e STEIN, 1977).

Com o decorrer da estruturação desse latifúndio, gerou-se também a relação de produção que se tornaria predominante em seu funcionamento interno: o sistema de peonagem. Com o fim da encomienda e do repartimiento, a queda da população, a decadência mineira e o aumento da importância dos latifúndios, os senhores de terra tinham que encontrar maneiras de sujeitar os indivíduos ao trabalho subordinado, ao invés destes se voltarem para a cultura de subsistência individual. Deste modo, os "amos" antecipavam dinheiro aos trabalhadores a fim de atraí-los ao trabalho em sua hacienda, pagava seus tributos à coroa, os vestia e cuidava em caso de enfermidades. Todos esses "favores" geravam uma dívida, na maioria das vezes, impagável, que prendia o trabalhador à terra. Outro elemento que reforçaria os endividamentos é a tienda de raya, um lugar dentro da hacienda que vendia tudo o que os peões precisavam, por um preço de monopólio, e marcavam com listras (rayas) as dívidas dos compradores. Tinha-se, portanto, um trabalhador pretensamente livre, mas, na prática, retido por dívidas (CHEVALIER, 1956).

Além do sistema de peonagem e de seus peones acasillados, submetidos ao domínio patriarcal direto do hacendado, tinham-se outras variações de trabalhadores que se ocupavam nas haciendas. Provenientes de comunidades vizinhas e trabalhando por temporadas, havia os peones eventuales, cujo hacendado pressionava as comunidades para obtê-los de acordo com suas necessidades flutuantes. Existiam também os jornaleros trashumantes, que não estavam ligados às comunidades. Por fim, os arrendatários e aparceros recebiam do hacendado parcelas de terra, sementes, instrumentos e às vezes casa, em troca de entregar-Ihe uma parte da colheita, uma soma de dinheiro ou ambos. Além disso, deveriam ajudar nos trabalhos das terras da hacienda (SEMO, 1978)

Acompanhado a isso, tem-se uma descentralização jurídica, de tal forma que o "amo" se apropria do direito de castigar e encarcerar seus peões. Para Hobsbawm (2017, pp. 115-16), do ponto de vista da organização interna, as haciendas só podem ser descritas como feudais. No entanto, essas relações de "vassalagem ou servidão" não são apenas resquícios do passado, "mas são, sob certas circunstâncias, reforçadas e elaboradas devido ao aumento da produção para o mercado". O senhor de terras não se preocupava com grandes aumentos de produtividade e tinha uma "atitude quase feudal do homem que se importava menos com a riqueza que sua terra produzia do que com o prestígio de possuir grandes territórios e o controle sobre um grande número de pessoas que viviam nele, ou sob sua dominação". O grande problema para os latifundiários não era aumentar a produção e investir em melhores técnicas, mas controlar o mercado disponível, monopolizar a terra e dominar a mão de obra.

As haciendas demoraram mais para se desenvolver nas zonas costeiras do golfo e do pacífico, mais quentes, onde a população indígena era menor que no planalto. Com exceção de algumas plantações pontuais de açúcar e de cacau, predominava nessas regiões fazendas de gado, trabalhadas por escravos negros e alguns trabalhadores livres. É no planalto central que se desenvolve a forma clássica da hacienda, com seus peões colocados sob a autoridade e a proteção dos seus amos (CHEVALIER, 1956).

Como o mercado interno era limitado e o externo instável, a economia natural sempre foi bastante presente e necessária na reprodução da vida no México colonial, e não foi diferente em relação às haciendas. Estas contavam quase sempre com 
terras de pastoreio, bosques e mananciais de água. Apenas uma parte da terra se utilizava para a produção mercantil, outra parte se utilizava para recompensar os trabalhadores em substituição ao pagamento em dinheiro e outras porções por vezes se tornavam ociosas pela incapacidade de absorver seus produtos. Desta forma, a quantidade de terra sob cultivo intenso para o mercado foi sempre restrita e, tanto as fazendas pastoris, engenhos de açúcar, minas e haciendas, tendiam a produzir internamente a maior parte do que necessitavam. Apenas uma parte dos produtos adquiriam o caráter de mercadoria e chegavam ao mercado (SEMO, 1987). Conforme Semo (Ibidem, p. 258):

La hacienda es un fruto idóneo de una sociedad en la cual feudalismo y economía mercantil se entretejen indisolublemente. Tiene una doble función: la de servir alternativamente como unidad autárquica y productora mercantil. A lo largo de los siglos XVII-XIX presenciamos un movimiento de sístole y diástole que hace de la hacienda una unidad predominantemente mercantil en periodos de expansión del mercado y decididamente autárquica en períodos de contracción. En ese sobre carácter de la hacienda, presente desde su origen, y en su adaptabilidad a las pulsaciones de un mercado sometido a poderosas presiones externas, reside el secreto de su estabilidad. ${ }^{21}$

Analisando esta realidade, podemos encontrar uma aproximação do pensamento de Lênin, quando diz que:

The population of a country in which commodity economy is poorly developed (or not developed at all) is almost exclusively agricultural. This, however, must not be understood as meaning that the population is engaged solely in agriculture: it only means that the population engaged in agriculture, also process the products of agriculture, and that exchange and the division of labour are almost non-existent (1977, p. 40$)^{22}$

Desse modo, baseados em I. Rangel (2005a), notamos que a economia da hacienda apresentava um setor ligado à economia natural, onde o trabalhador produzia seus instrumentos e equipamentos de trabalho, bem como todos os seus bens de consumo; e um outro setor, ligado à economia de mercado pré-capitalista, onde a especialização produtiva e a divisão social do trabalho era maior e mais aprofundada; a distribuição de fatores entre esses dois setores, no entanto, era regulada pelos estímulos externos do comércio exterior, ou setor "resto do mundo". A esse sistema, Rangel chamou de complexo rural.

Em conjunturas expansivas, aprofunda-se a divisão internacional do trabalho e, em conjunturas depressivas, diversifica-se a produção e substitui-se importações. Essa contração no comércio exterior pode gerar três movimentos diferentes de

\footnotetext{
${ }^{21}$ A hacienda é fruto idôneo de uma sociedade na qual o feudalismo e a economia mercantil se entrelaçam indissoluvelmente. Tem-se uma dupla função: a de servir alternativamente como unidade autárquica e produtora mercantil. Ao longo dos séculos XVII-XIX presenciamos um movimento de sístole e diástole que faz a hacienda uma unidade predominantemente mercantil em períodos de expansão do mercado e decididamente autárquica em períodos de contração. Nesse duplo caráter da hacienda, presente desde sua origem, e em sua adaptação às pulsações de um mercado submetido a poderosas pressões externas, reside o segredo de sua estabilidade (tradução livre nossa)

22 A população de um país de economia mercantil pouco desenvolvida (ou não desenvolvida de todo) é quase exclusivamente agrícola; disso, entretanto, não se deve deduzir que se ocupe apenas na agricultura; significa unicamente que a população ocupada na agricultura transforma ela própria os produtos da terra, sendo então quase inexistentes o intercâmbio e a divisão social do trabalho (LÊNIN, 1977, p. 40, tradução livre nossa)
} 
realocação de fatores, sendo eles: 1) o aumento da economia natural; 2) a substituição artesanal de importação no âmbito da economia de mercado précapitalista; 3) ou ainda, a substituição industrial de importações via investimentos produtivos em capital constante e recrutamento de mão-de-obra da economia précapitalista e da economia natural ${ }^{23}$.

Disso, podemos tirar conclusões mais gerais a respeito do processo de desenvolvimento econômico no México, seja ele que: obedecendo a estímulos do comércio exterior (ou setor "resto do mundo") leva-se a mudanças qualitativas da estrutura produtiva, transformando a economia natural em pequena produção mercantil, ou da pequena produção mercantil em indústria. Desse modo, a dinâmica de crescimento econômico não é somente resultado da qualificação da mão de obra e do aumento da intensidade dos meios de produção, mas também expressão do aprofundamento da divisão social do trabalho e do alargamento da economia de mercado. O processo de dissolução do complexo rural é também um processo de liberação de fatores, paralelamente a um processo de elevação da produtividade via aprofundamento da divisão social do trabalho que, levado às últimas consequências, resulta na mecanização do trabalho, o que, no México, só se concretizou com mais vigor no século $X X$.

O desmantelamento das haciendas se deu apenas com o advento da Revolução Mexicana de 1910 e seus desdobramentos, sobretudo com a ascensão ao poder de Lázaro Cárdenas (1934-1940), responsável pela maior reforma agrária da história do país, que distribuiu 17.890 hectares de terras (BARBOSA, 2010). A revolução marca o fim de um ciclo de revoluções burguesas que remontam a própria revolução de independência (1810-1821), passando pela Guerra da Reforma, importante passo para a construção de um Estado moderno separado da lgreja, até chegar na Revolução Mexicana, liderado inicialmente pelo pequeno-burguês Francisco I. Madero e tendo seu auge com a figura cardenista, principal responsável pela modernização industrial no México (SEMO, 1978).

\section{CONSIDERAÇÕES FINAIS}

Diferentemente do Brasil, cujos povos originários não formaram civilizações com alto nível de complexidade social, estrutura estratificada e grande domínio da agricultura, no México meridional estas sociedades floresceram, em contraste com a região setentrional em que predominaram tribos nômades. Com a conquista espanhola, a coroa feudal se apropria do aparato organizativo dessas grandes civilizações, realizando uma transição de poder pelo alto. A partir daí, a formação socioespacial mexicana se compõe de duas grandes determinações que guiarão o desenvolvimento de seu processo histórico: 1) as determinações internas, referente a esfera da produção, em que predominam relações de produção feudais, produto da transplantação das instituições espanholas e da absorção da estrutura social précolombiana; 2) O capital comercial da metrópole (Espanha), ainda ligado à sua coroa feudal.

\footnotetext{
23 Diferentemente do desenvolvimento periférico, que tende a se industrializar após uma contração externa, no desenvolvimento clássico se dá o contrário: desenvolve-se o setor capitalista através da expansão da exportação, que aumenta a capacidade de importar e libera fatores na parte do setor pré-capitalista voltada ao mercado interno, os quais são induzidos ao setor capitalista. Exemplo: "Um país antes produtor dos bens agrícolas que consome, desenvolve seu setor manufatureiro ou industrial com vistas a produzir um excedente exportável e, com a capacidade para importar resultante, compra ao exterior um suplemento de bens agrícolas, provocando assim uma contração do seu próprio setor agrícola, o qual libera fatores que, direta ou indiretamente, passam ao setor manufatureiro (Revolução industrial inglesa)” (RANGEL, 2005, p. 249).
} 
No decorrer de sua história e fortemente influenciada pelos fluxos e refluxos do comércio exterior, representante de suas relações externas, a economia mexicana passa por ciclos de substituições de importações e alargamento de sua economia de mercado pré-capitalista, via inserção da população presente na economia natural de subsistência. Vimos, com isso, que o desenvolvimento econômico no país não se resumiu ao aumento do capital constante no processo produtivo, como comumente pensam as teorias dualistas da CEPAL, mas também ao aprofundamento da divisão social do trabalho.

A teoria rangeliana da dualidade básica nos possibilitou identificar os diferentes modos de produção existentes na formação socioespacial mexicana e como estes se estruturam e se desenvolvem em seu processo de endogeneização do capitalismo. Ao superar a dicotomia entre produção e circulação, unindo-os em uma unidade de contrários, foi possível nos afastar de análises circulacionistas, que atribuem papel determinante ao capital comercial na transição ao capitalismo, caindo em análises generalizantes, que não se atém a totalidade social em sua dialética universal/particular. Desse modo, fortalece-se a ideia de que a teoria da dualidade básica representa a teoria e o método para se entender as formações sociais periféricas (RAMOS, 2019).

\section{AGRADECIMENTOS}

Os autores agradecem ao financiamento do CNPq (Conselho Nacional de Desenvolvimento Científico e Tecnológico), através de bolsa de mestrado, que possibilitou a produção deste artigo.

\section{REFERÊNCIAS BIBLIOGRÁFICAS}

BARBOSA, Carlos Alberto Sampaio. A Revolução Mexicana. São Paulo : Editora UNESP, 2010.

BASTOS, José Messias. Rangel e a Geografia. In: HOLANDA, Felipe Macedo et. al. (org). Ignácio3 Rangel, Decifrador do Brasil. São Luís : Edufma, 2014.

BATALLA, Angel Bassols. Geografía, subdesarrollo y regionalización: México y el tercer mundo. 5. ed. Editorial Nuestro Tiempo : México, 1979.

BIELSCHOWSKY, Ricardo. O pensamento econômico brasileiro: o ciclo ideológico do desenvolvimentismo. 5. ed. Rio de Janeiro : Contraponto, 2004.

BRENNER, Robert. The origins of capitalist development: a critique of neo-smithian marxism. New Left Review. $n^{\circ} 109,1977$

BRESSER-PEREIRA, Luiz Carlos. REGO, José Márcio. Um mestre da economia brasileira: Ignacio Rangel revisitado. In: Ignacio Rangel, Decifrador do Brasil. HOLANDA, Felipe Macedo et. al. (org). São Luís : Edufma, 2014.

CARDOSO, Ciro Flamarion; BRIGNOLI, Héctor Pérez. História econômica da América Latina. 2. ed. Rio de Janeiro : Edições Graal, 1984. 
CHEVALIER, François. La formación de los grandes latifundios en Mexico: tierra y sociedad en los siglos XVI y XVII. Problemas agrícolas e industriales en Mexico. $n^{\circ} 1$. vol VIII. Mexico, 1956.

CHOLLEY, A. Observações sobre alguns pontos de vista Geográficos. In: Boletim Geográfico. n. 179 (1a parte, p. 139-145), n. 180 (2a parte, p. 267-276). Rio de Janeiro: IBGE, 1964, p.139-145 e 267-276.

CONOCIMIENTOS FUNDAMENTALES. México y la Segunda Integración Mundial. Historia. UNAM, 2021. Disponível em: $<$ http://conocimientosfundamentales.rua.unam.mx/historia/Text/34_tema_03_3.1.2.ht $\mathrm{ml}$. Acesso em maio de 2021.

DOBB, Maurice. A evolução do capitalismo. 7. ed. Editora Guanabara ; Rio de Janeiro, 1987.

DONGHI, Halperin. História da América Latina. Rio de Janeiro : Editora Paz e Terra, 1974.

FURTADO, Celso. A economia latino-americana. 2. ed. São Paulo : Companhia Editora Nacional, 1978.

HOBSBAWM, Eric. Introdução. In: MARX, Karl. Formações econômicas précapitalistas. 6. ed. Paz e Terra, 1991.

HOBSBAWM, Eric. Viva la revolución: a era das utopias na América Latina. 1. ed. São Paulo : Companhia das Letras, 2017.

HUMBOLDT, Alexander Von. Ensayo político sobre la Nueva España. Tomo II. 2. ed. Paris, 1827.

JABBOUR, Elias. China hoje: projeto nacional, desenvolvimento e socialismo de mercado. $1^{\underline{a}}$ ed. São Paulo : Anita Garibaldi : Fundação Maurício Grabois : EDUEPB, 2012

LÊNIN, Vladímir llitch. Collected works: the development of capitalism in Russia. 3 vol. 4 ed. Progress Publishers Moscow, 1977. Disponível em: $<$ https://www.marxists.org/archive/lenin/works/cw/pdf/lenin-cw-vol-03.pdf>. Acesso em janeiro de 2021.

LÊNIN, Vladímir llitch. Capitalismo e agricultura nos Estados Unidos: novos dados sobre as leis de desenvolvimento do capitalismo na agricultura. São Paulo : Ed. Brasil Debates, 1980.

LÊNIN, Vladímir llitch. Cadernos filosóficos: Hegel. 1. ed. São Paulo : Boitempo, 2018.

LÊNIN, Vladímir llitch. Escritos da Juventude: volume 1. São Paulo : Lavrapalavra, 2020. 
MAMIGONIAN, Armen. A geografia e "a formação social como teoria e como método". In: SOUZA, Maria Adélia Aparecida (org.). $O$ mundo do cidadão, um cidadão do mundo. São Paulo : Hucitec, 1996.

MAMIGONIAN, Armen. Teorias sobre a industrialização brasileira. Cadernos Geográficos, Florianópolis: DGC/UFSC, n. 2, 2000.

MARX, Karl. Formações econômicas pré-capitalistas. 6. ed. Paz e Terra, 1991.

MARX, Karl. Contribuição à crítica da economia política. 2. ed. São Paulo : Expressão Popular, 2008.

MARX, Karl. O capital: crítica da economia política: livro I: o processo de produção do capital. 2. ed. São Paulo : Boitempo, 2017.

PEREIRA. Raquel Maria Fontes do Amaral. Da geografia que se ensina à gênese da geografia moderna. 4ํe. ed. Florianópolis : Ed. da UFSC, 2009.

RAMOS, João Victor Moré. A Dualidade básica como teoria e método das formações sociais periféricas. Anais XIII ENANPEGE. São Paulo, 2019.

RANGEL, Ignácio. Obras Reunidas/Ignácio Rangel. vol. 1. Rio de Janeiro: Ed. Contraponto, 2005a.

RANGEL, Ignácio. Obras Reunidas/Ignácio Rangel. vol. 2. Rio de Janeiro: Ed. Contraponto, 2005b.

SANTANA, José R. Hernandéz et al. Clasificación geomorfométrica del relieve mexicano: una aproximación morfográfica por densidad de curvas de nivel y la energía del relieve. Investigaciones Geográficas. vol. 97. 2017

SANTOS, Milton. Sociedade e Espaço: a formação social como teoria e como método. In: Espaço e sociedade. Petrópolis : Vozes, 1979.

SANTOS, Milton. Por uma geografia nova: da crítica da geografia a uma geografia crítica. 6. ed., São Paulo : Editora da Universidade de São Paulo, 2012.

SANTOS, Milton. A natureza do espaço: técnica e tempo, razão e emoção. 4. ed. São Paulo : Editora da Universidade de São Paulo, 2017.

SEMO, Enrique. Historia mexicana: economía y lucha de clases. Ediciones Era : México, 1978.

SEMO, Enrique. Historia del Capitalismo en México. Ciudad de México : Ed. Lecturas Mexicanas, 1987.

SERENI, Emilio. DE MARX A LÊNIN: a categoria de "formação económico-social". Revista de Geografia Meridiano. n², 2013. 
SILVA, Marcos Aurélio da. FES: Transições, vias de desenvolvimento e questões territoriais: uma abordagem a partir de Antonio Gramsci. Revista Bibliográfica de Geografía y Ciencias Sociales. Vol. 21. n`1.161, 2016.

STEIN, Stanley J; STEIN, Barbara H. A herança colonial da América Latina: ensaios de dependência econômica. 2. ed. Rio de Janeiro : Paz e Terra, 1977.

TROTSKY, Leon. História da revolução russa. 2. ed. Rio de Janeiro, Paz e Terra, 1977.

WOOD, Ellen Meiksins. O império do capital. 1. ed. São Paulo : Boitempo, 2014. 